\title{
Temperature-Dependence Study on the Hydrogen Transport Properties of Polymers Used for Hydrogen Infrastructure
}

\author{
Received 4 November, 2021; revised 19 November, 2021; accepted 23 November, 2021
}

\author{
Jin-Sub Jang ${ }^{a, b}\left(\mathbb{D}\right.$, Chunjoong Kim $^{b}$ (D), and Nak-Kwan Chung ${ }^{a, *(i)}$ \\ a Korea Research Institute of Standards and Science (KRISS), Daejeon 34113, Republic of Korea \\ bDepartment of Materials Science \& Engineering, Chungnam National University, Daejeon 34134, Republic of Korea
}

\author{
*Corresponding author E-mail: nk.chung@kriss.re.kr
}

\begin{abstract}
Polymeric materials used in hydrogen infrastructure degrade with temperature changes, thereby increasing the risk of hydrogen leakage. Therefore, it is essential to evaluate the hydrogen permeation characteristics at varying temperatures, particularly at low temperatures, for the safe use of hydrogen energy. This study aimed to measure hydrogen permeability at a temperature range of $243-313 \mathrm{~K}$ for exploring the hydrogen permeation characteristics according to the temperature of ethylene-propylene diene monomer (EPDM), fluorine-rubber (FKM), and nitrilebutadiene rubber (NBR) for hydrogen infrastructure. Results show that permeability and diffusivity rapidly decreased as the temperature decreased; however, there was no significant change in solubility with the variation in temperature. Activation energies of permeability, diffusivity, and solubility were calculated from the measurement results, among which the activation energy for permeability exhibited the largest value in the order of FKM, NBR, and EPDM.
\end{abstract}

Keywords: Hydrogen infrastructure, Polymers, Hydrogen permeation, Activation energy

\section{Introduction}

Polymeric materials are widely used in high-pressure hydrogen storage containers and sealing parts owing to its low weight and excellent moldability [1]. These polymers are exposed at various environmental temperatures ranging from $228-358 \mathrm{~K}$, which can induce the degradation of the polymer characteristics and blister fractures or ruptures $[2,3]$. Therefore, it is important to evaluate the hydrogen transport properties of polymers at various temperatures for the safety of the hydrogen infrastructure.

To date, several studies have investigated the hydrogen permeation properties of polymers under different temperature conditions [4-7]. Amerongen et al. measured the permeability (P), the diffusivity (D), and the solubility $(\mathrm{S})$ of various rubbers such as natural rubber, methyl rubber, and butyl rubber in the temperature range of 273-373 K and derived the activation energies $\left(\mathrm{E}_{\mathrm{P}}\right.$ and $\left.\mathrm{E}_{\mathrm{D}}\right)$ of $\mathrm{P}$ and $\mathrm{D}$ and the heat of sorption $\left(\Delta \mathrm{H}_{\mathrm{S}}\right)$ from the measured data. Humpenoder et al. [6] studied the gas permeation of plastics in the temperature range of 200-293 $\mathrm{K}$ and calculated their $\mathrm{E}_{\mathrm{P}}$ and $\mathrm{E}_{\mathrm{D}}$ of $\mathrm{P}$ and $\mathrm{D}$. However, few attempts have been made to measure the low-temperature transport properties of hydrogen in rubbers.

This study detailed the development of the hydrogen permeability testing apparatus equipped with a temperature control device, and

Table I. Hardness and glass transition temperatures of specimens.

\begin{tabular}{c|c|c}
\hline Polymer & Hardness (Shore A) & $\mathrm{T}_{\mathrm{g}}(\mathrm{K})$ \\
\hline EPDM & 95 & 215 \\
NBR & 75 & 252 \\
FKM & 90 & 265 \\
\hline
\end{tabular}

measured P, D, and S of EPDM, NBR, and FKM used in hydrogen infrastructures in the temperature range of $243-313 \mathrm{~K}$. Then, $\mathrm{E}_{\mathrm{P}}, \mathrm{E}_{\mathrm{D}}$, and $\Delta \mathrm{H}_{\mathrm{S}}$ were obtained from the linear slope of an Arrhenius plots of the logarithm of the data against inverse temperature.

\section{Experimental details}

\subsection{Materials}

The material used for the test was purchased in the form of a $1 \mathrm{~mm}$ thick sheet from Kraiburg TPE GmbH (Germany), with the hardness values listed in Table I. The glass transition temperatures $\left(\mathrm{T}_{\mathrm{g}}\right)$ were measured by differential scanning calorimetry (DMA 242E; ASTM1356), and the hardness values were provided by the supplier of the materials. For the measurements, the samples were cut into a circle of $35 \mathrm{~mm}$ in diameter and then washed with distilled water and ethanol, before finally drying in a vacuum chamber for two days to reduce its outgassing rate.

\subsection{Method}

Figure 1(a) shows a schematic of a device developed based on the differential-pressure method according to ISO 15105-1 [8]. The differential-pressure method follows Fick’s diffusion law and Henry's gas solubility law, whilst the parameters $\mathrm{P}, \mathrm{D}$, and $\mathrm{S}$ can be calculated using this method. The experimental procedures were as follows: a round sample of $35 \mathrm{~mm}$ diameter was mounted on the holder, and the chamber was evacuated using a dry pump for 1-2 days until the outgassing rate was lowered to less than $1 \times 10^{-7} \mathrm{~Pa} / \mathrm{s}$. After a sufficiently long 
(a)

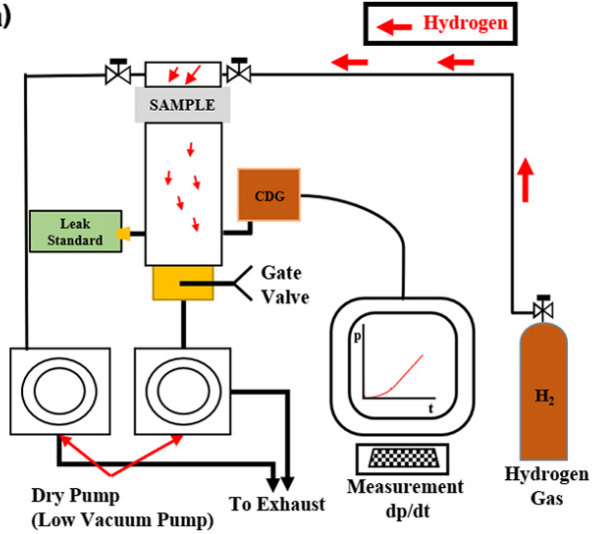

(b)

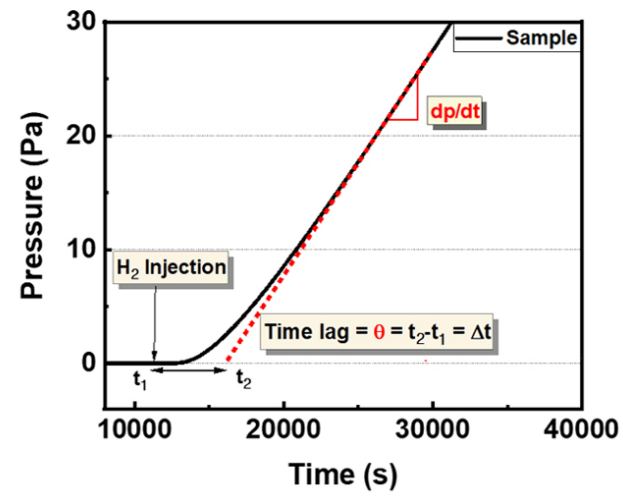

Figure 1. (a) Schematics of the hydrogen permeation measurement apparatus and (b) the representative hydrogen permeation curve through polymers.

time, the desired sample temperature was adjusted using a bath circulator. Then, the gate valve was closed and the rate of pressure rise was checked to ensure it did not rise above $1 \times 10^{-7} \mathrm{~Pa} / \mathrm{s}$. If the outgassing rate was sufficiently low, the valve in the high-pressure chamber was opened to bring hydrogen gas to $0.1 \mathrm{MPa}$ and the increase of the pressure in the low-pressure part was recorded and graphed. As shown in Fig. 1(b), the permeation curve of $d p / d t$ slope is slowly changed and the measurement is continued until the gas permeation reaches a constant rate.

From the graph, the slope $(d p / d t)$ can be obtained and $\mathrm{P}$ can be calculated from Eq. (1) [8]:

$$
\mathrm{P}=\frac{1}{R T P_{\text {ext }}} \times V_{c} \times \frac{d p}{d t} \times \frac{d}{A}
$$

where $R, T, P_{\text {ext }}, V_{c}, p, d$, and $A$ are the ideal gas constant $\left[8.31 \times 10^{3}\right.$ $1 \cdot \mathrm{Pa} / \mathrm{K} \cdot \mathrm{mol}]$, a sample temperature $[\mathrm{K}]$, an external hydrogen pressure $[\mathrm{Pa}]$, a chamber volume $\left[\mathrm{m}^{3}\right]$, a pressure in the measurement chamber, the thickness of a sample $[\mathrm{m}]$, and the area of a sample $\left[\mathrm{m}^{2}\right]$, respectively.

Therefore, $\mathrm{D}$ can be deduced from the time lag value as follows [8].

$$
\mathrm{D}=\frac{d^{2}}{6 \theta}
$$

Table II. Hydrogen transport properties of rubbers at $296 \mathrm{~K}$.

\begin{tabular}{c|c|c|c}
\hline Polymer & $\begin{array}{c}\text { Permeability } \\
{\left[\mathrm{mol} \cdot \mathrm{m} /\left(\mathrm{m}^{2} \cdot \mathrm{s} \cdot \mathrm{MPa}\right)\right]}\end{array}$ & $\begin{array}{c}\text { Diffusivity } \\
\left(\mathrm{m}^{2} / \mathrm{s}\right)\end{array}$ & $\begin{array}{c}\text { Solubility } \\
{\left[\mathrm{mol} /\left(\mathrm{m}^{3} \cdot \mathrm{MPa}\right)\right]}\end{array}$ \\
\hline EPDM & 17.2 & 5.2 & 33.4 \\
NBR & 3.8 & 0.9 & 42.8 \\
FKM & 2.1 & 0.8 & 26.4 \\
\hline
\end{tabular}

(a)
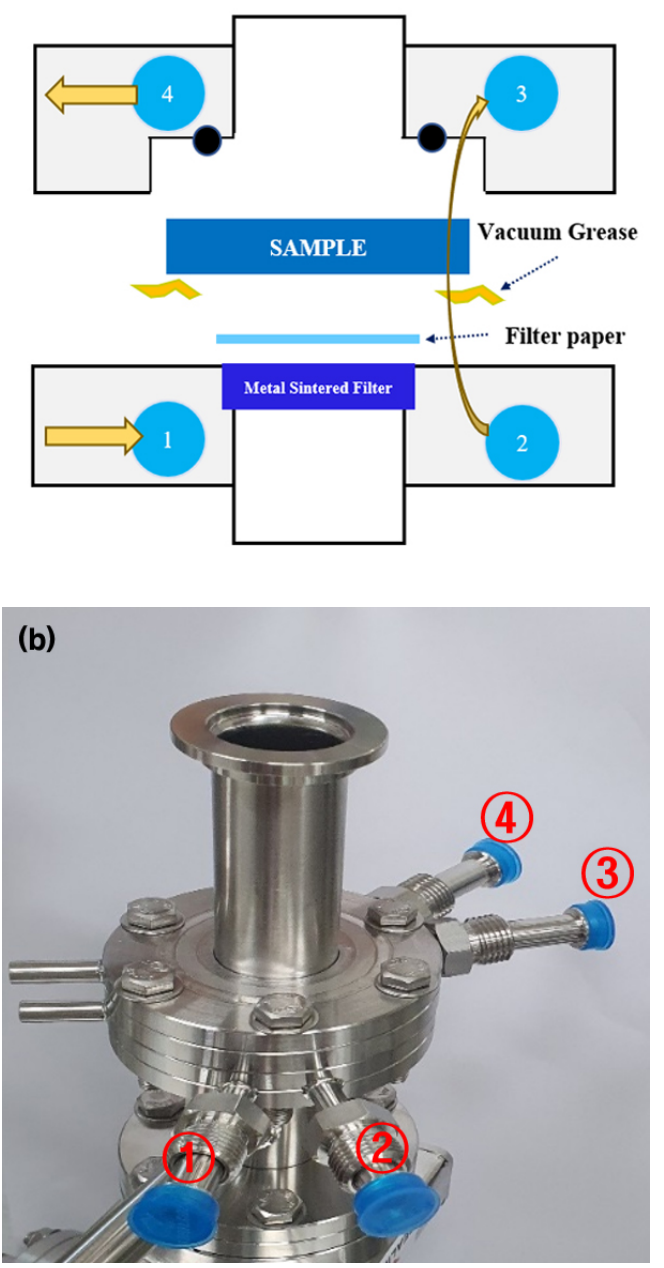

Figure 2. (a) Schematics of the temperature-controlled cell and (b) its photograph. The bath fluid circulates into the cell in the order 1 to 4 .

Finally, $\mathrm{S}$ can be obtained from $\mathrm{P}$ and $\mathrm{D}$ as follows.

$$
\mathrm{S}=\frac{P}{D}
$$

Figure 2 shows the schematic of the temperature-controlled sample holder and its photograph. Vacuum grease was used to ensure tight sealing between the sample and the holder. Filter paper was inserted between the sample and the metal-sintered filter to allow the permeated gases to be released into the measurement chamber, and its diameter is equal to the inner diameter of the O-ring to clearly define the effective permeation area of the sample. The sample holders were maintained at the set temperature using a circulating bath, and the bath fluid circulates into the cell from one to four. Additional thermal insulating jackets were used (not shown); later, it was confirmed the

Table III. Hydrogen transport properties of EPDM at various temperatures.

\begin{tabular}{c|c|c|c}
\hline $\begin{array}{c}\text { Temperature } \\
(\mathrm{K})\end{array}$ & $\begin{array}{c}\text { Permeability } \\
10^{-9}\left[\mathrm{~mol} \cdot \mathrm{m} /\left(\mathrm{m}^{2} \cdot \mathrm{s} \cdot \mathrm{MPa}\right)\right]\end{array}$ & $\begin{array}{c}\text { Diffusivity } \\
10^{-10}\left(\mathrm{~m}^{2} / \mathrm{s}\right)\end{array}$ & $\begin{array}{c}\text { Solubility } \\
{\left[\mathrm{mol} /\left(\mathrm{m}^{3} \cdot \mathrm{MPa}\right)\right]}\end{array}$ \\
\hline 296 & 17.2 & 5.2 & 33.4 \\
283 & 7.9 & 2.6 & 30.2 \\
273 & 5.3 & 1.5 & 34.1 \\
263 & 2.8 & 0.7 & 36.0 \\
253 & 1.2 & 0.4 & 29.5 \\
243 & 0.6 & 0.2 & 37.2 \\
\hline
\end{tabular}




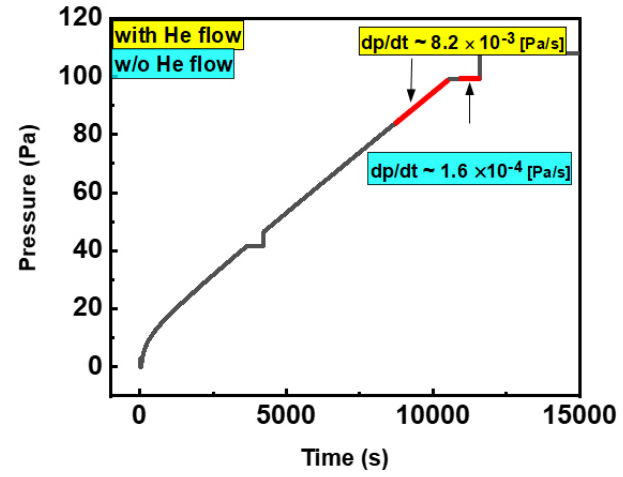

Figure 3. The pressure-rise curve by a flow injection using He leak standard. The curve is fitted after the He injection $(t=0)$.

temperature difference between the set value of the bath and the cell was within $5 \mathrm{~K}$, and the temperature was then set to the desired value.

To establish traceability to national flow standards, the proposed system was calibrated with the helium leak standard and the capacitance diaphragm gauge was also calibrated with the low-vacuum primary standard in KRISS [9]. Figure 3 shows a rate-of-rise curve in the system due to helium flow from the leak standard [10], and the background pressure rise $\left(d p^{\prime} / d t\right)$ due to outgassing rate (q) of the system was $1.6 \times 10^{-4} \mathrm{~Pa} / \mathrm{s}$ before He injection.

The pressure rises $(d p / d t)$ became $8.2 \times 10^{-3} \mathrm{~Pa} / \mathrm{s}$ when He was injected. Finally, the outgassing rate $(Q)$ was obtained using Eq. (4) with the volume of the system being $\mathrm{V}=6.22 \times 10^{-5} \mathrm{~m}^{3}$.

$$
\mathrm{Q}=\mathrm{V} \cdot\left(\frac{d p}{d t}-\frac{d p^{\prime}}{d t}\right)
$$

\section{Results and discussion}

Figure 4 shows the curves of hydrogen permeation of EPDM, NBR and FKM at room temperature $(296 \mathrm{~K})$. The pressure increase rates of EPDM, NBR, and FKM were $1.8 \times 10^{-2}, 4.6 \times 10^{-3}$, and $2.1 \times 10^{-3} \mathrm{~Pa} / \mathrm{s}$, respectively, while the time-lags were measured as 2267,10297 , and $13032 \mathrm{~s}$, respectively. According to Eqs. (1)-(3), P, D, and S of the samples were calculated and are listed in Table II. Similar to previous studies, FKM exhibits the lowest $\mathrm{P}$ for hydrogen gas at room temperature. It was also determined that D of EPDM was much larger than

Table IV. Hydrogen transport properties of NBR at various temperatures.

\begin{tabular}{c|c|c|c}
\hline $\begin{array}{c}\text { Temperature } \\
(\mathrm{K})\end{array}$ & $\begin{array}{c}\text { Permeability } \\
10^{-9}\left[\mathrm{~mol} \cdot \mathrm{m} /\left(\mathrm{m}^{2} \cdot \mathrm{s} \cdot \mathrm{MPa}\right)\right]\end{array}$ & $\begin{array}{c}\text { Diffusivity } \\
10^{-10}\left(\mathrm{~m}^{2} / \mathrm{s}\right)\end{array}$ & $\begin{array}{c}\text { Solubility } \\
{\left[\mathrm{mol} /\left(\mathrm{m}^{3} \cdot \mathrm{MPa}\right)\right]}\end{array}$ \\
\hline 303 & 5.0 & 1.3 & 38.6 \\
296 & 3.8 & 0.9 & 42.8 \\
283 & 1.6 & 0.4 & 46.3 \\
273 & 0.8 & 0.2 & 38.4 \\
263 & 0.2 & 0.2 & 10.8 \\
253 & 0.0 & - & - \\
\hline
\end{tabular}

Table V. Hydrogen transport properties of FKM at various temperatures.

\begin{tabular}{c|c|c|c}
\hline $\begin{array}{c}\text { Temperature } \\
(\mathrm{K})\end{array}$ & $\begin{array}{c}\text { Permeability } \\
{\left[\mathrm{mol} \cdot \mathrm{m} /\left(\mathrm{m}^{2} \cdot \mathrm{s} \cdot \mathrm{MPa}\right)\right]}\end{array}$ & $\begin{array}{c}\text { Diffusivity } \\
\left(\mathrm{m}^{2} / \mathrm{s}\right)\end{array}$ & $\begin{array}{c}\text { Solubility } \\
{\left[\mathrm{mol} /\left(\mathrm{m}^{3} \cdot \mathrm{MPa}\right)\right]}\end{array}$ \\
\hline 313 & 6.4 & 2.8 & 27.3 \\
303 & 3.0 & 1.1 & 26.8 \\
296 & 1.9 & 1.1 & 16.5 \\
283 & 0.9 & 0.4 & 25.2 \\
273 & 0.4 & 0.2 & 14.4 \\
263 & 0.0 & - & - \\
\hline
\end{tabular}

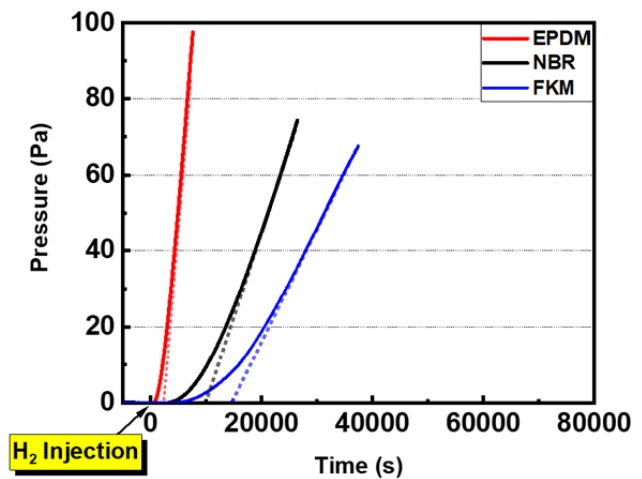

Figure 4. Hydrogen permeation curves of EPDM, NBR, and FKM. The curves are obtained after the $\mathrm{H}_{2}$ injection $(\mathrm{t}=0)$, and the dotted lines describe the tangent obtained after the $\mathrm{H}_{2}$ injection $(\mathrm{t}=0)$
line to obtain the pressure-rise rate.

those of NBR and FKM, whilst S was relatively similar. Therefore, it can be seen that the hydrogen transport property in rubber is more related to $\mathrm{D}$ than $\mathrm{S}[2-5]$.

To analyze the effects of temperature on the hydrogen transport properties of rubbers, this study measured the $\mathrm{P}, \mathrm{D}$, and $\mathrm{S}$ in a temperature range of $243-313 \mathrm{~K}$. As shown in Table III-V, the P and D of rubber rapidly decrease as the T decreases. Finally, although EPDM is highly permeable to hydrogen below $253 \mathrm{~K}$, the permeation through NBR and FKM were not observed even after $72 \mathrm{~h}$ experiments. Although $\mathrm{S}$ exhibited extremely weak temperature dependency, those of NBR and FKM abruptly decreased below 263 and $273 \mathrm{~K}$, respectively. Therefore, it was determined that the rubbery characteristics of NBR and FKM begin to transition to the glassy and rigid states from approximately $10 \mathrm{~K}$ above $\mathrm{T}_{\mathrm{g}}$ [13].

To explore the temperature dependence of $\mathrm{P}, \mathrm{D}$, and $\mathrm{S}$ of the rubbers, the data was fitted with the Arrhenius equations for P, D and S [14]:

$$
\begin{aligned}
& P=P_{0} \exp \left(\frac{-E_{P}}{R T}\right) \\
& D=D_{0} \exp \left(\frac{-E_{D}}{R T}\right) \\
& S=S_{0} \exp \left(\frac{-\Delta H_{S}}{R T}\right)
\end{aligned}
$$

where $\mathrm{P}_{0}, \mathrm{D}_{0}$, and $\mathrm{S}_{0}$ are the pre-exponential factors, $\mathrm{E}_{\mathrm{p}}, \mathrm{E}_{\mathrm{D}}$, and $\Delta \mathrm{H}_{\mathrm{S}}$ are the activation energy of permeation and diffusion and the heat of sorption, $\mathrm{T}$ is the temperature, and $\mathrm{R}$ is the ideal gas constant. The parameters $\mathrm{E}_{\mathrm{P}}, \mathrm{E}_{\mathrm{D}}$, and $\Delta \mathrm{H}_{\mathrm{S}}$ were determined from the slopes of the least-squares regression lines from the data, as shown in Fig. 5. The values in the open symbols were excluded from the calculation of $E_{P}$, $\mathrm{E}_{\mathrm{D}}$, and $\Delta \mathrm{H}_{\mathrm{S}}$ for the rubbery states. The activation energies and the heat of sorption of the rubbers calculated with the filled symbols in Fig. 5 are listed in Table VI. The $\mathrm{E}_{\mathrm{P}}$ of FKM was the highest, followed by that of NBR and EPDM. Notably, $\mathrm{E}_{\mathrm{D}}$ exhibited a similar trend with $\mathrm{E}_{\mathrm{P}}$ whilst $\Delta \mathrm{H}_{\mathrm{S}}$ was extremely low. The value of $\mathrm{S}$ was hardly affected by temperature, indicating an extremely small temperature dependence. Therefore, it can be seen that the permeation properties are mainly related to $\mathrm{D}[10,11]$.

Table VI. Hydrogen transport properties of rubbers.

\begin{tabular}{c|c|c|c|c}
\hline Material & $\begin{array}{c}\text { Temperature } \\
\text { Range }(\mathrm{K})\end{array}$ & $\begin{array}{c}\mathrm{E}_{\mathrm{P}} \\
(\mathrm{kJ} / \mathrm{mol})\end{array}$ & $\begin{array}{c}\mathrm{E}_{\mathrm{D}} \\
(\mathrm{kJ} / \mathrm{mol})\end{array}$ & $\begin{array}{c}\Delta \mathrm{H}_{\mathrm{S}} \\
(\mathrm{kJ} / \mathrm{mol})\end{array}$ \\
\hline EPDM & $253-296$ & 37.9 & 37.3 & 0.5 \\
NBR & $273-303$ & 41.5 & 42.0 & -0.5 \\
FKM & $283-313$ & 47.5 & 44.9 & 2.1 \\
\hline
\end{tabular}


(a)

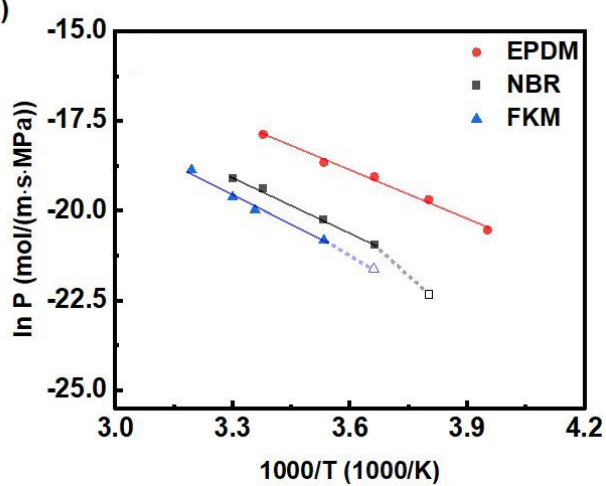

(b)

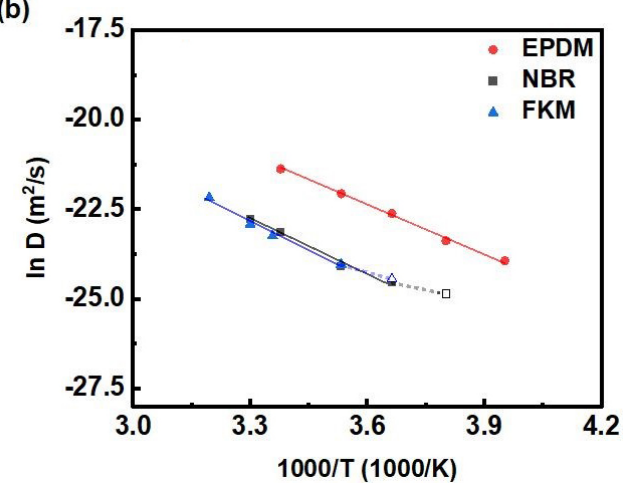

(c)

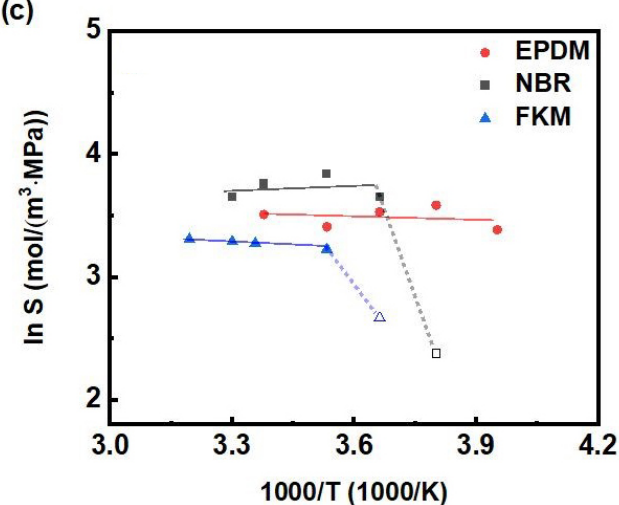

Figure 5. The Arrhenius plots of (a) permeability, (b) diffusivity, and (c) solubility of EPDM, NBR, and FKM. The filled symbols represent the data obtained above their $T_{g}$, that is, in the rubbery state and the open symbols represent the data obtained near or below their $\mathrm{T}_{\mathrm{g}}$, that is, in the glassy state.

\section{Conclusions}

This study measured P, D, and S of EPDM, NBR, and FKM in a temperature range between $253-313 \mathrm{~K}$. As the temperature decreased, it was observed that $\mathrm{P}$ and $\mathrm{D}$ rapidly decreased, while in contrast, $\mathrm{S}$ exhibited less temperature dependence. The activation energies of per- meation and diffusion as well as the heat of sorption of the rubbers were determined from the slope of the Arrhenius plot of each material. As a result, it was concluded that the activation energy of the hydrogen permeation is higher in FKM than in NBR, and EPDM has the lowest value among them.

\section{Acknowledgements}

This work was supported by the 2019 2021 KAIA/MOLIT Project (No. 19TLRP-C152334-01) leaded by Korea Research Institute of Standards and Science (KRISS), Republic of Korea, and Development of Reliability Measurement Technology for Hydrogen Refueling Station funded by KRISS (KRISS - 2021 - GP2021-0007).

\section{Conflicts of Interest}

The authors declare no conflicts of interest.

\section{ORCID}

Jin-Sub Jang

Chunjoong Kim

Nak-Kwan Chung https://orcid.org/0000-0001-9219-3847 https://orcid.org/0000-0002-8881-3422 https://orcid.org/0000-0002-9608-2201

\section{References}

[1] R. R. Barth, K. L. Simmons, and C. San Marchi, Sandia Report No. SAND2013-8904, 2013.

[2] J. Yamabe and S. Nishimura, Int. J. Hydrog. Energy 34, 1977 (2009).

[3] R. M. Barrer and E. K. Ridal, Trans. Faraday Soc. 35, 628 (1939).

[4] G. J. Van Amerongen, C. Koningsberger, and G. Salomon, J. Polym. Sci. 6, 639 (1950).

[5] G. J. Van Amerongen, J. Appl. Phys. 17, 972 (1946).

[6] J. Humpenoder, Cryogenics 38, 143 (1998).

[7] J. Jang and N. Chung, Proceedings of the ASME 2020 Pressure Vessels \& Piping Conference of the Pressure Vessels and Piping Division, edited by ASME (Virtual, Online, August 3, 2020) Vol. 1, pp. V001T01A041.

[8] ISO (the International Organization for Standardization) https://www.iso.org/standard/41677.html (accessed Nov. 24, 2021).

[9] S. Hong, J. Kim, and Y. Shin, Meas. Sci. Technol. 19, 015102 (2008).

[10] Y. Shin, S. Hong, I. Lim, and K. Chung, Key Eng. Mater. 270-273, 1674 (2004).

[11] T. Komatsuka and K. Nagai, Polym. J. 41, 455 (2009).

[12] M. H. Klopffer and B. Flaconneche, Oil Gas Sci. Technol. 56, 223 (2001).

[13] H. Yasuda and T. Hirotsu, J. Appl. Polym. Sci. 21, 105 (1977).

[14] S. C. George and S. Thomas, Prog. Polym. Sci. 26, 985 (2001). 